\title{
The therapeutic alliance with involuntary clients: how does it work?
}

\author{
Luciana Sotero, ${ }^{\text {a }}$ Sofia Major, ${ }^{\mathrm{b}}$ Valentín Escudero ${ }^{\mathrm{c}}$ \\ and Ana Paula Relvas ${ }^{\mathrm{d}}$
}

This study aimed to compare involuntary and voluntary clients in the establishment of the therapeutic alliance in the context of family therapy. The system for observing family therapy alliances was used to rate the alliance in sessions 1 and 4 from videotapes of 40 families seen in brief family therapy. This instrument has four alliance dimensions. In the first session, results showed that the clients who sought therapy voluntarily demonstrated more alliance-related behaviour than did involuntary clients in all alliance dimensions. In the fourth session, however, only the Engagement dimension showed group differences. Notably, there also were group differences in the evolution of the alliance from the first to the fourth session in the Safety dimension, with the voluntary clients developing this dimension more negatively. The results are discussed in terms of the specific characteristics of involuntary clients, as well as the implications for practice.

\section{Practitioner points}

- Be aware of differing motives, motivations, and degrees of readiness for therapy within the family

- Inquire about the amount of pressure experienced by clients, and the source of that pressure, early in the family therapy

- Promote and monitor the therapeutic alliance with involuntary clients

- Promote a safe context, providing structure and guidelines for safety and confidentiality and helping clients to talk truthfully

Keywords: therapeutic alliance; involuntary clients; family therapy; SOFTA.

a Visiting Assistant Lecturer, Faculty of Psychology and Education Sciences, University of Coimbra, Rua do Colégio Novo, 3001-802 Coimbra, Portugal. E-mail: lucianasotero @fpce.uc.pt.

b Visiting Assistant Professor, Faculty of Psychology and Education Sciences, University of Coimbra.

c Professor, Department of Psychology, University of A Coruña, Campus de Elviña 15071, A Coruña, Spain.

d Professor, Faculty of Psychology and Education Sciences, University of Coimbra. 


\section{Introduction}

Therapeutic intervention with involuntary clients can be considered a major challenge for therapists but also for clients (Sotero and Relvas, 2012), for several reasons, such as ethical dilemmas, motivational issues and alliance problems. The psychotherapeutic work carried out with clients who do not spontaneously apply for help but who are referred, pressured or mandated to participate in therapy is commonly described as complex or frustrating (Tohn and Oshlag, 1996), despite the significant contributions of some studies on how to work with them (for example, Higham et al., 2012; Trotter, 2006; Weakland and Jordan, 1992). The actual circumstances of involuntary referral for therapy sometimes make professionals feel as reluctant to work with involuntary clients as clients themselves do; these therapists have even come to be labelled 'involuntary practitioners' (Rooney, 1992, p. 6). Furthermore, professional training (in therapy if not in professions like social work) usually assumes that clients are self-selected, while in fact most therapists eventually work with clients who come to therapy because of a court order or through the pressure of referral sources, other people or family members. According to the distinction made by some authors (Rooney, 1992), involuntary clients may include two subsets: mandated clients who are legally referred to therapy (for example, by state agencies or the law court), and non-voluntary ones who do not seek help spontaneously, although the source of pressure is not a legal one.

One of the issues highlighted in the literature on involuntary intervention concerns the difficulties in establishing and maintaining a good therapeutic alliance with such clients (Friedlander et al., 2006; Honea-Boles and Griffin, 2001; Snyder and Anderson, 2009). In the present study, we began with the general question: how can we generate a good alliance with people who did not look for help voluntarily? How can we develop a strong alliance with clients who are angry because they were coerced into being with the therapist? The assessment of the therapeutic alliance with these clients becomes even more relevant when we consider the results of several studies that show the alliance to be a significant predictor of the success of the therapy, particularly when measured at the beginning of the intervention (Horvath et al., 2011).

Thus, the present study aimed to assess the establishment and development of the therapeutic alliance with involuntary clients by comparison with a group of voluntary ones in the context of systemic family therapy. 


\section{Why the therapeutic alliance?}

When considering a common factors approach, a sustained interest in the therapeutic alliance is evident, which, by definition, is a joint product of both therapist and client (Sprenkle et al., 2009). According to Bordin's (1979) conceptual model the alliance is composed of three elements: bonds (the affective quality of the therapist-client relationship, which includes dimensions such as trust, care and engagement); tasks (the agreement between client and therapist on the tasks carried out in the therapy) and goals (the extent to which client and therapist work together in order to achieve compatible goals). Research indicates clearly that the alliance is a very important and powerful variable in therapeutic outcome, both in individual (Horvath et al., 2011) and in family therapy (Escudero et al., 2008; Friedlander et al., 2011). There is evidence that treatment retention as well as therapeutic outcomes can be predicted from a therapeutic alliance established early in the therapy, before any specific therapy procedures have been applied (Lambert and Ogles, 2004; Martin et al., 2000).

Among the common factors, client variables appear as one of the major sources of variance in psychotherapy (Duncan and Miller, 2000; Sprenkle and Blow, 2004). These relate to (i) personal characteristics (like the individual's motivation level, commitment to change, internal resources and religious faith) and (ii) extra-therapeutic factors in the client's social life (for example, social support, involvement in the community and stressful events). Although there is some research focusing on the socio-demographic characteristics of clients (such as their age, race, gender and sexual orientation), most studies have shown that these characteristics do not have relevant correlations with therapy outcomes (Sprenkle et al., 2009). On the other hand, few studies have been developed concerning the clients' non-static characteristics (for example, their level of commitment, emotional expression and level of motivation). From this point of view, Sprenkle and Blow (2004) draw attention to the lack of research on the motivational characteristics of clients in family therapy, which may correlate directly with involvement and collaboration in treatment and with a willingness to participate in therapy. Consequently, these are the client variables that may be strongly related to the therapeutic alliance and to the therapy outcome.

The topic of alliance in the context of therapeutic intervention with involuntary families is important, therefore, and it appears to be 
necessary to understand how the alliance is (or is not) affected when working with clients who are seen as uncooperative or do not want to be in therapy. The aim of the present study is, indeed, to explore how the voluntary or involuntary status, as a client variable, and the alliance, as a therapeutic relationship variable, are related to and influence each other.

\section{The case of conjoint therapies}

The way the therapeutic alliance with involuntary clients is developed and maintained has been neglected in individual psychotherapy, but ignored and forgotten even more in family therapy (Snyder and Anderson, 2009). Family therapists very often work with clients who did not voluntarily seek help, clients who were referred, pressured or mandated by agencies or elements outside the family (such as schools, courts, child protection services, family doctors and employers). However, family and even couple therapy can often also emerge from pressure within the family. Children, adolescents and one member of a couple are examples of clients who are in therapy because other members of the family 'forced' them to be there. It may happen that these people recognize that they need help or that they need to change something in their lives, but the choice to seek professional help was not theirs. In the case of family therapy, the challenge of dealing with one (or more than one) family member's unwillingness to attend the therapy is even greater because the therapist must also have the ability to develop a good therapeutic alliance with each individual in particular, and with the family as a whole (Sprenkle and Blow, 2004). The presence of more than one client in the session, their different developmental levels and variety of reasons and motivations for being in therapy, make the building and maintenance of the therapeutic alliance in conjoint therapies a more complex process (Escudero et al., 2010).

In this type of therapeutic format, alliances develop simultaneously at the individual level and at group level. As in individual therapy, in conjoint therapies, the alliance involves the development of a strong emotional connection with the therapist, as well as the negotiation of goals and tasks. Moreover, multiple alliances interacting systematically will coexist throughout the intervention (Pinsof, 1994). In this sense, the alliance dimension of the family as a whole, which is more than the sum of its parts, has been alternatively conceptualized as an allegiance (Symonds and Horvath, 2004), a within-family alliance (Pinsof, 1994) 
and a shared sense of purpose within the family (Friedlander et al., 2006). These constructs refer not only to the willingness to cooperate in therapy, but also to a strong emotional bond among family members (Friedlander et al., 2011). The evaluation of the alliance in conjoint therapies thus implies attention not only to individual alliances between clients and therapist but also to the alliance that family members establish with one another.

Another important aspect of the alliance in family therapy is the degree of safety and comfort of each element in the therapeutic context. The sense of safety related to other family members is an important and unique dimension of the therapeutic alliance in conjoint therapy (Friedlander et al., 2006). Unlike what happens in individual therapy, what is revealed in the sessions (secrets, conflicts, feelings) will have an impact at home and on the everyday life of the family. When family members realize the implications of what is said in the sessions and feel that what they say can be used against each other outside the sessions, their sense of safety within the therapeutic context and their trust in the therapist are at risk. Moreover, the degree of safety within the therapeutic system also changes when new problems are revealed or explored and when different family members participate in or quit therapy (Beck et al., 2006).

Conflicting motives and ambivalence about participating (or not participating) in therapy are common components of the therapeutic process when working with families, but particularly with involuntary families who engage in therapy as a result of pressure or referral from a third party. To be clear, we stress that when talking about involuntary families in the present study one should keep in mind that these families were referred to family therapy as a whole. In these circumstances we have to face multiple situations. There are cases in which all family members identify themselves as involuntary, assuming the position that they do not want to be there and do not wish to engage in the therapeutic process. We may also face other situations in which some members want to be part of the process and others do not (the most frequent situation). Finally, in some cases it is difficult to perceive whether some members of the family want to engage in therapy or not, as there appears to be a covert refusal. If we add to these possibilities the fact that the (in)voluntary self-perception status is not static and changes over time (for example, someone who began therapy involuntarily may spontaneously desire therapeutic help after one or two sessions), it becomes easy to see that the task of identifying 
involuntary and voluntary families and clients is complex (Sotero and Relvas, 2012). Perhaps this may partially explain why research in this area is scarce and many questions about therapeutic intervention with involuntary clients remain unanswered, despite the considerable frequency with which therapists work with these clients and the lack of specific intervention models to deal with involuntary clients' conditions.

As far as we know, there are no studies on the therapeutic alliance with involuntary clients in the context of conjoint family therapy, although we can find 'few but solid' (Friedlander et al., 2011, p. 31) analyses of the alliance in family therapy. A recent meta-analysis of 24 published studies indicates that the association between alliance and outcome was statistically significant and accounted for a substantial proportion of variance in couple and family therapy retention and outcome (Friedlander et al., 2011). The weighted average effect size was $r=.26, z=8.13(P<0.005)$, with a $95 \%$ confidence interval of .33 and .20. According to conventional benchmarks, an $r$ of .26 $(d=.53)$ is a small-to-medium effect size in the behavioural sciences; this value is quite similar to the $r=.275$ reported by Horvath et al. (2011) on the alliance in individual therapy. The same authors state that, despite the few studies on moderator and mediator variables of the alliance, the literature indicates three important alliance-related phenomena: (i) the frequency and impact of split alliances (when there is evidence of a positive alliance with the therapist in one member or subsystem of the family and a negative or weak alliance in another family member of subsystem), (ii) the importance of creating a safe therapy context, and (iii) the need to promote a strong sense of shared purpose within the family (Friedlander et al., 2011). Concerning therapy with involuntary clients, Friedlander et al. (2006) also hypothesize that lack of safety within the therapeutic system and poor levels of shared sense of purpose within the family would be obvious signs of the involuntary nature of the therapeutic relationship.

Therefore, the general goal of this study is to test whether there are significant differences in the strength of the therapeutic alliance established by the members of involuntary families compared with voluntary ones. As specific goals we aimed to (i) compare the alliancerelated behaviour established by the two groups in sessions 1 and 4 (between-group comparative analysis) and (ii) analyse the evolution of the strength of the alliance from session 1 to session 4 in each group as well as between groups (within and between-group comparative analysis). 


\section{Method}

\section{Participants}

We describe the study participants both as families and as individuals, since our unit of analysis was the family, although using individual as well as family group measures. The sample was composed of 40 families $(N=131$ individuals; all family members attending therapy), divided into two groups: 20 involuntary families $(n=68$ individuals) and 20 voluntary families $(n=63$ individuals). Treatment demands included intra-family conflicts, communication problems, difficulties in adjusting to family ruptures (such as separation, divorce and grief), and parenting difficulties. From the 20 involuntary families who met the selection criteria (explained below), five cases were referred by a school, five by mental health services, four by health centres and six by public child protective services. Only six cases could be classified as mandated families (Rooney, 1992) in the sense of being in therapy because of a legal obligation or court order.

In all 27 cases completed the therapy and 13 were dropouts. They were distributed in the subsamples as follows: 10 completed cases and 10 dropouts in the involuntary families group, and 17 completed cases versus three dropouts in the voluntary group $\left(\chi^{2}(1)=4.10, P=\right.$ $0.043)$. It is important to note, in all the ensuing analysis, the varied rates of dropout in each group.

The first and fourth sessions were analysed for the study. Of the total sample of 131 individual participants (that is, sessions 1 and 4 combined), 127 family members attended in session 1 (four involuntary participants missed session 1), and only 91 family members attended in session 4 (28 involuntary and 12 voluntary participants missed that session). All sessions analysed included at least two family members.

According to the categorization proposed by Relvas (1996) the two groups did not differ in the stage of the family life cycle. Families with adolescent children (35\%) and families with children at school (35\%) constituted the majority $(70 \%)$ of the family sample. As for sociodemographic variables (age, gender and educational level), there were no statistically significant differences between the participants in the two groups (age $\chi^{2}(6)=11.08, P=0.09$; sex $\chi^{2}(1)=.099, P=$ 0.75 ; educational level $\left.\chi^{2}(5)=9.22, P=0.10\right)$.

Most participants were two-parent families $(n=24)$. The sample included 39 mothers, 25 fathers, one grandfather, two girlfriends 
and 39 children and teens (aged 6-16). All clients were Portuguese Caucasian, aged between 5 and 70 years $(M=28.92$ and $\mathrm{SD}=16.45)$, with a balanced distribution of both genders (56\% female). In all, 45 per cent of the clients had a basic educational level $\left(1^{\text {st }}, 2^{\text {nd }}[\right.$ corresponding to primary school] or $3^{\text {rd }}$ study cycle [corresponding to secondary school]).

Sample selection and determination of involuntary versus voluntary condition

The families were selected from the archive of a Portuguese university centre of systemic family therapy. Initially, we analysed all archived clinical cases concluded between 2000 and $2009(N=130)$. The families were divided into two groups, involuntary and voluntary, according to the following inclusion criteria:

Involuntary families. (i) By analysing the therapy demand form, all cases that had been referred to therapy by a private or public institutional service (for example, child protection services, schools, and health centres) were selected. Using this criterion 73 cases were identified as involuntary. They were then randomized in order to constitute a random subgroup of 20 involuntary cases. (ii) A detailed analysis of the written records of the clinical files of those 20 cases (including the demand form, first session report and therapists' notes) was made to eliminate any case that did not meet a second condition: that more than half of the present family members had clearly said they did not want, need or believe in the usefulness of therapy. Each eliminated case was replaced by another chosen at random and the criteria were applied systematically until the group of 20 clear cases of involuntary families was completed.

Voluntary families. Procedures to categorize voluntary families were as follows. (i) Among the clinical cases characterized by a spontaneous appeal for help, that is, where the demand was made by a family member without an external referral, 39 cases were identified as voluntary. They were then also randomized to set up a subgroup of 20 voluntary cases. (ii) A detailed analysis of the written records of those 20 clinical files was made to eliminate any case that did not meet a second condition: that no family member had said they did not want or need the treatment or that they did not believe in the usefulness of therapy. A similar procedure to the one described in the involuntary 
group selection was used to replace these eliminated cases, until the 20-case sample was completed.

Among the 130 clinical cases originally analysed, an undefined source of demand was found in 18 cases, so they, too, were eliminated in a preliminary stage of the selection process described above. The main objective of the second criterion was to clean up the subsamples of doubtful cases, that is, the cases in which most family members expressed their explicit desire for therapy, despite a demand made by a third party (false involuntary) and the cases in which some of the family elements (or only one of them) explicitly expressed their opposition to therapy, despite a spontaneous demand for therapy (false voluntary).

\section{Treatment conditions}

The collected data refer to time-limited systemic interventions, with two co-therapists and an observation team behind the one-way mirror adopting an integrative model of short-term family therapy (6-9 sessions, spaced from 3 to 4 weeks). This model assumes a second order epistemological perspective, characterized by a curious position and a search for multiple descriptions (Nichols and Schwartz, 2006; Relvas, 2003). Every session included a break and a final comment or reframing, together with regularly prescribed task(s) (Relvas, 2003). The average number of sessions for this sample was $6.64(\mathrm{SD}=3.25)$. Video recording is a standard practice in this therapy centre, and all the clients had given their consent for the recording of the sessions and their use in research. Families were allocated to therapists based on schedule availability. There were 31 family therapists involved in the selected therapeutic processes, 24 women and seven men, aged between 22 and $49(M=31.39, \mathrm{SD}=7.31)$, with a clinical experience varying from 1 to 20 years $(M=6.30, \mathrm{SD}=6.07)$. Most therapists $(75 \%)$ had specific training in family therapy and systemic intervention, while the remainder $(25 \%)$ were trainees from the final year of an integrated Master's course in clinical psychology. Each therapist followed on average 2.55 cases $(\mathrm{SD}=2.20)$ and $39 \%(n=12)$ participated in both involuntary and voluntary clinical cases.

\section{Instrument}

System for Observing Family Therapy Alliances (SOFTA-o) (Friedlander et al., 2006). This instrument, which enables us to evaluate the strength of the therapeutic alliance (client and therapist versions), was 
developed simultaneously in the USA and in Spain, and is based on a multidimensional and trans-theoretical definition of the construct. In the client version SOFTA-o allows us to evaluate the alliance by means of the observable behaviour of clients (verbal and nonverbal, positive and negative) throughout the therapy sessions. The behaviour is grouped into four dimensions, as follows.

1. Engagement in the therapeutic process (for example, The client expresses their agreement with the goals proposed by the therapist). A high score on this dimension indicates that the client considers the treatment to be important, feels involved in the therapy and works together with the therapist in the definition and negotiation of the goals and tasks of the process.

2. Emotional connection with the therapist (for example, The client avoids eye contact with the therapist). This dimension enables us to assess whether the client sees the therapist as an important person in their life and feels that the relationship is based on trust, affection, interest and a sense of belonging.

3. Safety within the therapeutic system (for example, The client reveals a secret or something that no other family member knows about). This dimension includes behavioural indicators that the client sees (or does not see) therapy as a context in which they can take risks and be open and flexible.

4. Shared sense of purpose within the family (for example, Family members blame one another). This dimension evaluates the sense of unity and solidarity of family members in relation to therapy, making it possible to realize the extent to which family members see themselves as working together in order to improve family relationships and achieve common goals.

To rate the sessions with SOFTA-o, trained observers watch the videos and take notes on the observation of the behavioural descriptors included in the training manual (Friedlander et al., 2005; see www.softa-soatif.net). The manual provides guidelines for this task. At the end, each dimension is scored according to the type, frequency and intensity of the behavioural indicators, the score ranging from -3 (extremely problematic) to +3 (extremely strong), where 0 corresponds to not remarkable or neutral. Thus, each family member receives a score on the strength of the alliance in the engagement, connection and safety dimensions, while the family as a whole is scored on shared sense of purpose. Across five studies, SOFTA-o authors found intra-class correlations (ICC) ranging from .72 to .95 
(Friedlander et al., 2006). The present study used the Portuguese version of observational SOFTA-o (client's version) (Friedlander et al., 2006), translated by Sotero et al. (2010).

Rating procedures. In the present study 69 video-taped sessions were rated by four raters (two PhD students in family intervention and two MA students in clinical psychology). Of these 40 were first sessions ( $n$ $=127$ individuals) and 29 were fourth sessions ( $n=91$ individuals; as we note above, 11 families quit therapy before session 4 ). We chose to rate sessions 1 and 4 in order to obtain data from the initial and middle stage of therapy. All family members were rated on every individual dimension of the SOFTA-o, following the SOFTA-o manual instructions. The rating team had been trained for approximately 20 hours with practice video tapes to obtain adequate levels of reliability (ICC ranging from .75 to .97). Then, without the three raters' knowledge of the purpose of the study, a subsample of sessions (25\%) was rated by them to assess interrater reliability (ICCs ranging from .83 to .98). After this reliability test all sessions were rated independently; raters met regularly to negotiate all discrepancies to set the final ratings. In this study the total sample's ICCs were engagement .96, emotional connection .97, safety .97, and shared sense of purpose .99, indicating good interrater reliability.

\section{Results}

Comparative analyses

Involuntary versus voluntary families' therapeutic alliance (sessions 1 and 4). In the independent comparative analysis for each of the three alliance individual dimensions, the $t$-tests showed significant differences in the first sessions for all dimensions (engagement $t[117]=-4.76, P \leq$ 0.001 ; connection $t[125]=-2.26, P=0.025$; safety $t[125]=-3.52$, $P \leq 0.001$ ) (see Figure 1). The results indicate that in the involuntary group the observed alliances were weaker. To understand the magnitude of the observed differences, effect sizes were calculated based on Cohen's $d$ statistic (Cohen, 1988) when independent groups are analysed ( $d$; see Morris and DeShon, 2002), where a $d$ of .20 is small, .50 is medium, and .80 is large. Based on these standards, the effect sizes were large in engagement $(d=.85)$, medium in safety $(d=.63)$ and small in connection $(d=.41)$. Between-group comparisons made for session 4 only showed a significant difference for engagement $(t[89]=$ $-3.08, P<0.01)$ between the involuntary $(M=0.98, \mathrm{SD}=0.80)$ and voluntary $(M=1.49, \mathrm{SD}=0.78)$ groups (associated with a moderated 


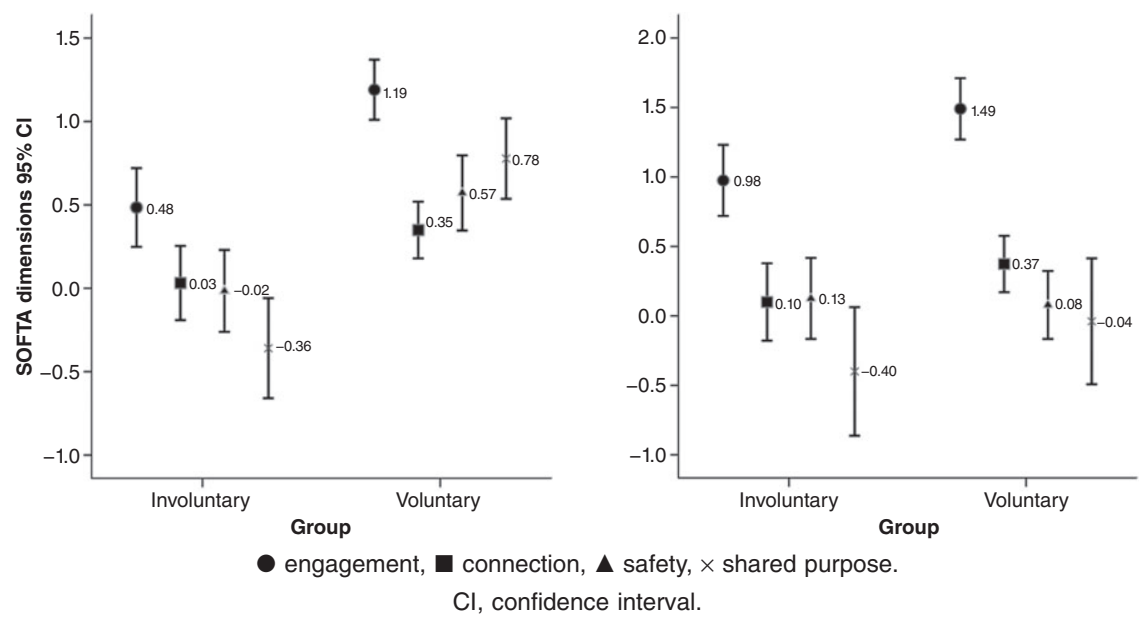

Figure 1. Therapeutic alliance in Figure 2. Therapeutic alliance in session 1.

session 4.

effect size of .65) (see Figure 2). The results for the shared purpose of the family as a whole indicated differences between groups in the first session $(t[120])=-5.91, P \leq 0.001)$ but did not in the fourth session. In the involuntary group the alliance was always weaker. The magnitude of the differences in the first session was extensive in shared purpose $(d=1.04)$.

Figures 1 and 2 also show that in session 1 only the involuntary group obtained negative mean values in alliance dimensions, namely in safety and shared purpose, while in session 4 negative mean values were just observed in shared purpose for both groups.

Between-group comparisons of the therapeutic alliance evolution (from session 1 to session 4). A $2 \times 2$ mixed ANOVA - two groups (involuntary versus voluntary) $\times$ two sessions (alliance change over time from session 1 to session 4) for each SOFTA dimension was conducted. Obviously, the cases with a single session could not be used in these analyses, so a subsample including the participants who attended both sessions was used (involuntary $n=36$; voluntary $n=51$ ). Because Cohen's $d$ becomes less convenient in multivariate designs in which comparisons are more complex than simply the difference between two means, we described the effect sizes through the partial eta squared 


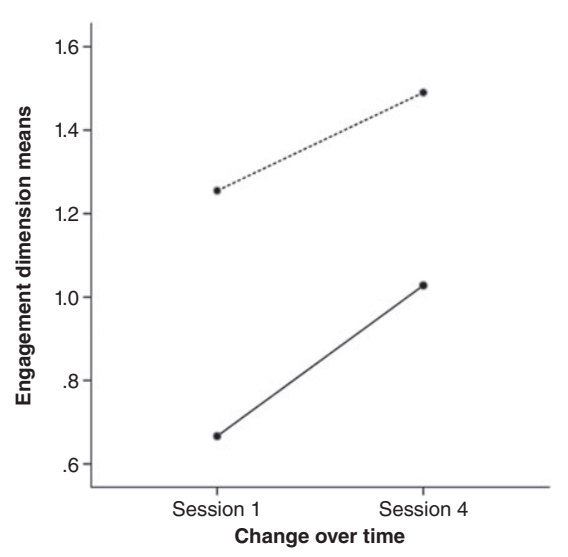

— involuntary group,

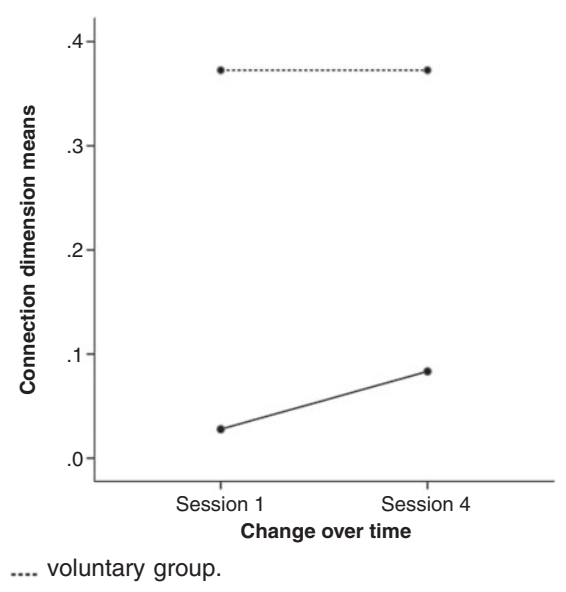

Figure 4. Between-group comparisons for connection dimension (session 1 to 4 ).

$\left(\eta_{p}{ }^{2} ; .01=\right.$ small effect, $.09=$ moderate effect, $.25=$ large effect $)$ (Tabachnick and Fidell, 2007).

There was a significant effect for time, $F(1,85)=8.45, P<0.01, \eta_{p}{ }^{2}$ $=.09$ (moderate effect), showing that engagement in session 4 was significantly higher than at the beginning of the therapy (session 1). A significant effect for group was also found, $F(1,85)=14.63, P<0.01$, $\eta_{p}{ }^{2}=.15$ (moderate effect), indicating that the involuntary group has weaker engagement than the voluntary. The interaction effect, $F(1,85)$ $=0.38$, NS, did not reach statistical significance (see Figure 3).

For connection there was no statistically significant main effect for time, $F(1,85)=0.09$, NS, nor for the interaction effect $F(1,85)=0.09$, NS. Only the main effect of group on connection was significant $F(1,85)=5.10, P<0.05, \eta_{p}{ }^{2}=.06$ (small effect), indicating that in the involuntary group the emotional connection to the therapist was weaker than in the voluntary group (see Figure 4).

As indicated in Figure 5, from session 1 to 4 safety decreased significantly, $F(1,85)=7.80, P<0.01, \eta_{p}{ }^{2}=.08$ (small effect), showing a main effect for safety over time. Also the main effect of group on the safety scores was significant, $F(1,85)=6.51, P<0.05, \eta_{p}{ }^{2}=.07$ (small effect). A significant effect for the interaction, $F(1,85)=6.45, P<0.05$, $\eta_{p}{ }^{2}=.07$, indicates that there were significant differences in the effect of therapy over time on the safety dimension for involuntary and 


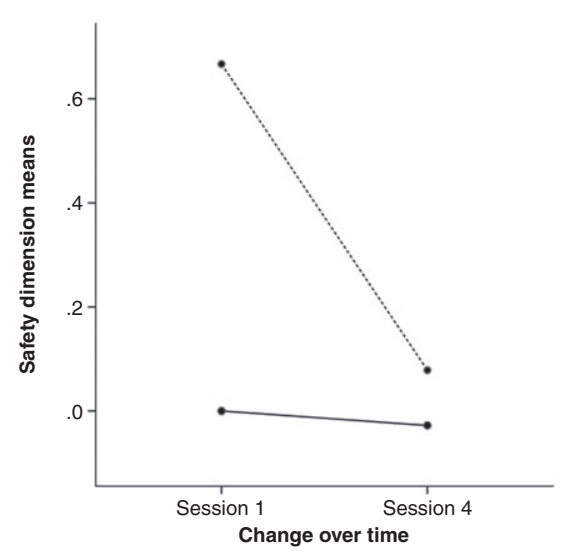

— involuntary group,

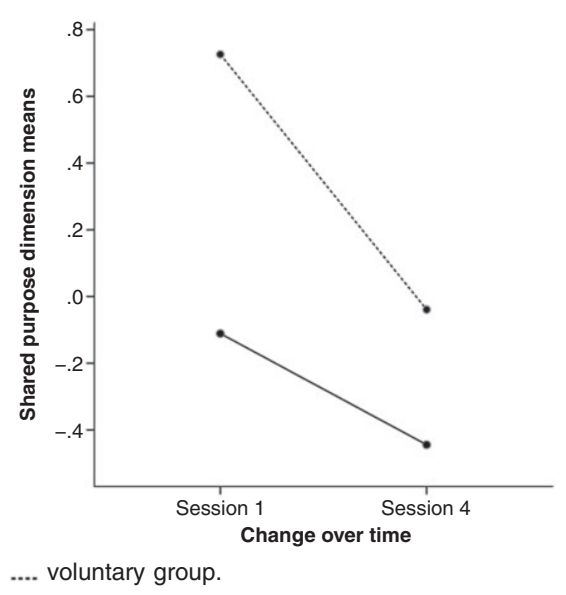

Figure 6. Between-group comparisons for shared purpose dimension (session 1 to 4 ).

voluntary groups. Although both groups decreased in safety across time there was a much stronger effect when clients were voluntary.

Figure 6 shows a significant main effect for shared purpose over time, $F(1,85)=17.85, P<0.01, \eta_{p}{ }^{2}=.17$ (moderate effect). In session 4 the global family's scores in the shared purpose dimension were lower than those at the beginning of the therapy (session 1). The main effect of group on the shared purpose family scores was significant, $F(1,85)=6.35, P<0.05, \eta_{p}{ }^{2}=.07$ (small effect). The shared purpose over time $\times$ group interaction was not significant; $F(1,85)=2.75$, NS.

\section{Discussion}

The results obtained showed that, in the first session, involuntary families differed from voluntary ones both in individual and group family alliance. Furthermore, they diverged in all specific dimensions of the alliance. These were expected results. Families who experienced pressure to attend therapy and are referred by a third party (involuntary group) emerged as being significantly less engaged, less emotionally connected to the therapist and less safe within the therapeutic context. As a family, they showed less shared sense of purpose than voluntary families. In other words, the present study shows that, at the beginning of the therapy, involuntary clients 
establish significantly weaker alliances than voluntary ones. These results corroborate the idea that most clients who initiate a therapeutic process unintentionally are less open to therapy, less cooperative and less motivated to change (Miller and Rollnick, 2002; Rooney, 1992).

Although these results are very interesting and reinforce the idea that it is challenging to establish therapeutic alliances with involuntary families, particularly at the beginning of therapy, it is important to remember that in our sample there were more dropouts in the involuntary group than in the voluntary one. To some extent this was expected because some research has shown that dropouts are frequent among clients for whom therapy is mandated (Rempel and Destefano, 2002). In fact, the aim of this study was not to predict dropouts from the initial motivational conditions of clients, but to study (through behavioural observation) how the alliance works in a sample of involuntary versus voluntary families. The point was to analyse how therapy works with involuntary clients who are obliged to be in therapy, so those who choose not to start or not to enter or remain in the therapy were not our focus. If we had eliminated the dropout cases this would have biased the sample and might have weighted the results towards the less involuntary families in the involuntary group! It seems to us that future research on the dropout issue requires a deeper discussion of the concept (such as clarifying the criteria for establishing dropping out, such as whether to use the number of sessions as the cutoff or basing it on a clinical criteria defined by the therapist).

Similar results are also shared with some studies carried out with clients in the motivation stages of pre-contemplation and contemplation of change (Prochaska and DiClemente, 1984), who often are involuntary clients. Earlier in therapy those clients have a lower probability of developing a strong alliance than clients with higher levels of motivation (Connors et al., 2000). Recently a study about the complex interrelationships between distress, referral source, pressure to attend therapy, and motivation to change concluded that the relationship between pressure and referral source was not significant (Moore et al., 2013). While the source of the referral did not seem to be important, the pressure felt by clients did. Those clients are likely to have lower levels of motivation to change. This conclusion is even more important if we take into account the couple and family therapy case because clients often present for therapy at the behest of someone, usually a family member. 
Involuntary clients, and particularly mandated clients, often come from poor and multi-stressed (Madsen, 2007) families. Cultural, social factors and family patterns of these clients (Imber-Black, 1988) may sometimes be misunderstood by therapists who do not share their context. This might itself contribute to aspects of feeling forced to attend therapy, especially when it is provided by services that are seen to be negative and to represent the state (Honea-Boles and Griffin, 2001). As argued by Friedlander et al. (2006), when the referring agency has a strained relationship with the family and the family feels threatened or pressured, the logical conclusion must be that this family will see the therapist as an extension of that agency.

However, in the present study the involuntary families did not differ from the voluntary ones in socio-demographic characteristics (such as educational level); besides, there were only six mandated families in the sample (referred by public child protective services) and only one quit therapy before the fourth session. Moreover, involuntary clients didn't show negative emotional connections with the therapists in any of the analysed sessions, although in the first session the voluntary clients evidenced a stronger bond with therapists. So, the present results do not evidence negative relationships with professionals. However, these families were seen in a clinical service that accepts both voluntary and involuntary clients, which might be different from a social services setting where typically all clients are involuntary. This particular contextual difference should not be ignored when interpreting the results; in fact it seems an interesting variable to take into account in future studies.

In the first session, we can remark that alliance negative values were observed only in the involuntary families, namely in safety and shared sense of purpose. These findings suggest a particularly problematic alliance in these dimensions. Thus, it is possible to speculate that the problem is not so much located or related with the therapist as with the therapeutic context itself (not enough safety to be in therapy with the other members of the family). These clients somehow felt the context not appropriate enough to take risks, be comfortable or be flexible. On the other hand, we could expect that shared sense of purpose within the family (togetherness and solidarity of family members in relation to therapy, making family members see themselves as working together in order to improve family relationships and achieve common goals) would be hard to accomplish in involuntary families. In fact, (i) they were usually referred because of the behaviour of one of their members (identified patient), (ii) the other 
members of the family felt that they did not deserve the 'punishment' of being in therapy, and (iii) they frequently saw themselves as split into good and bad. So, our findings support the hypothesis of Friedlander et al. (2006) that these two dimensions are probably the most crucial when clients, in addition to not recognizing the existence of a problem, also perceive the referral to therapy as unfair (an almost hostage attitude). Accordingly, ensuring safety within the therapeutic system and promoting a shared sense of purpose within the family are of upmost importance for the establishment of therapeutic alliance in these cases (Friedlander et al., 2006).

When the clients' distrust of the intervention is significant, it is difficult to create a safe space for sharing and trust, as a therapeutic context should be. The fear that information will be disclosed is even greater since, in some cases, family members know that the therapist makes reports on their behaviour or is in contact with the referring person or agency. The difficulty of the therapists who work under these circumstances lies in the risk of losing the role of agent of change and becoming an agent of social control (Honea-Boles and Griffin, 2001). In the family therapy centre where the sample was collected, in spite of there being no strict rules on information sharing and contacts between the therapists and the referring person or agency, those contacts are usually minimal. Besides, when reports are required their content is usually shared and discussed with the clients.

The engagement of these clients in therapy may represent a further challenge to therapists (De Jong and Berg, 2001; Honea-Boles and Griffin, 2001; Rooney, 1992). The challenge can be even greater if therapists are not able to anticipate and normalize the rejection and defensiveness of clients. In these cases, the frustration of therapists may lead them to blame their clients and react with anger when they are hostile (Snyder and Anderson, 2009). The alternative is for therapists to resist the temptation of being scandalized when involuntary clients do not want to take part in therapy and to construe the negative reactions of clients as an expectable initial reaction (Snyder and Anderson, 2009) or as an essential task to work on in the initial stages of the treatment (Friedlander et al., 2006).

The differences between involuntary and voluntary families in the middle stage of the therapeutic process faded. This could be a significant and inspiring finding of the present study. By session 4 they differed only in the engagement dimension, with the involuntary clients showing weaker alliances. Furthermore, all the individual 
alliance dimensions were positive both in involuntary and voluntary groups. These results may indicate that the therapeutic process promotes some convergence between involuntary and voluntary families in alliance behaviour. In fact, there was a significant improvement from session 1 to 4 in engagement in involuntary families (in fact, it was the only dimension where we observe a significant improvement). We can assume that engagement may evolve positively along the therapy, although remaining a problematic dimension when compared with voluntary families.

Unexpectedly, voluntary families worsened significantly in safety and shared purpose in session 4 . It is possible that in this middle stage of the process, voluntary families' initial openness to therapy may result in behaviour and feelings that lead to discomfort. This may in turn lead to family members feeling less secure and happy with each other. This is essentially the process of change. These results point towards the conclusions of other authors, namely, that sustaining the alliance is not a steady, uniform process but rather a discontinuous one (Escudero et al., 2008; Higham et al., 2012). In this sense, effective therapy with families involves two seemingly contradictory adaptations (Friedlander et al., 2006). According to Escudero et al. (2008) the degree to which safety is possible for a given family member depends on many factors in the family system itself (conflicts, tensions and intimidation) other than the therapist's attitude or techniques. Notably, in a series of case studies (Beck et al., 2006), some clients' observed ratings of safety changed dramatically depending on which members of the family attended the session. Indeed, feeling vulnerable at some point during treatment is so closely associated with therapeutic change that many therapists consider it a necessary part of the process (Friedlander et al., 2006).

Although these findings provide evidence about how the alliance unfolds differently for families who are involuntary compared with families who began therapy voluntarily, we must bear in mind some limitations that may affect or bias the interpretation of the results. The first is that the strength of the alliance was measured only at two different moments throughout the process. This prevents the researcher from obtaining a better understanding of the evolution of the alliance along the process. Secondly, while the heterogeneity of the family members attending the sessions is characteristic of naturalistic research, the diversity of the subsystems present in the sessions adds complexity to the interpretation of results. Thirdly, no therapeutic alliance self-reports of the participants (both family members and 
therapists) were used. Next, this study does not provide responses about how the problem of differences in the dropout cases between the groups influences the differential formation of alliances. Future research should focus specifically on how the dropout variable influences the therapeutic alliance and also on how the therapeutic alliance could change the dropout rates in voluntary versus involuntary cases. Finally, the therapist variables were not contemplated in the analysis (namely, their contributions to alliance).

\section{Conclusion}

From this study we can underline some main conclusions on involuntary families' therapeutic alliance: (i) at the beginning of the therapy the strength of alliance is significantly weaker in every dimension from that of voluntary families, and (ii) by the fourth session these differences fade. Surprisingly when considering the evolution of alliance from first to fourth session, voluntary families decreased their sense of safety in therapy significantly more than involuntary ones. This finding could indicate the importance of further research to have a better knowledge of the evolution of patterns of alliance throughout the family therapy process and the way it relates with therapeutic change.

\section{Implications for therapy}

When family members have differing motives, motivations and degrees of readiness for therapy, several interacting alliances need to be monitored simultaneously. Therapists should pay particular attention to the therapeutic strategies that can lead the families to feel themselves in danger as a unit. For example, when the therapist fails to address one client's stated concerns by only discussing the concerns of another client; or fails to intervene when family members argue with each other about the goals, value or need for therapy. They also need to promote a safe context for these families, facilitating their involvement in therapy. Namely, the therapist should encourage clients to articulate their goals for therapy, providing structure and guidelines for safety and confidentiality and helping clients to talk truthfully and not defensively to each other. Furthermore, therapists should inquire about the amount of pressure experienced by clients, and the source of that pressure, early in the therapy (Moore et al., 2013). Therapist training and supervision should take these issues into account. 


\section{Future directions}

Some interesting questions about the establishment of the therapeutic alliance with involuntary clients arise as research challenges for the future: how does the alliance, in these cases, relate to the therapeutic results? What is the role of therapists in the establishment of the alliance with those clients? Can we also speak of involuntary therapists? What strategies may increase the strength of the alliance with those clients? So, in order to find some answers to those questions and to raise new ones, we intend to continue the study on therapeutic alliance in family therapy with involuntary families developing studies focused on: (i) the comparison of therapists' alliance behaviour with voluntary and involuntary families; (ii) the development and testing of . a model-thes relates the SOFTA's alliance clients' and therapists' . . . . dimensions. with the improvement in therapy, defining some media- tors and..... related to family characteristics (such as involuntary families with adolescents), specific referrals (for example, mandated families versus non-voluntary families) and by outcomes (dropouts versus completed .

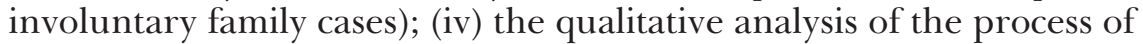

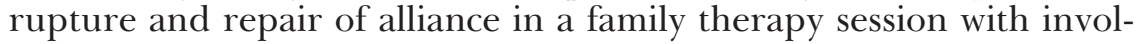

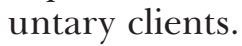

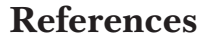

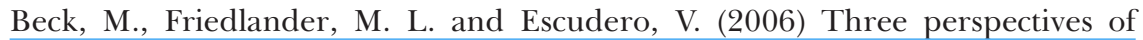

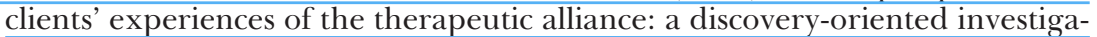

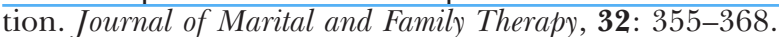

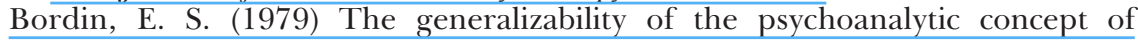
the working alliance. Psychotherapy: Theory, Research and Practice, 16: 252260.

Cohen, J. (1988) Statistical Power Analysis for the Behavioral Sciences (2nd edn). Mahwah, NJ: Lawrence Erlbaum.

Connors, G. J., DiClemente, C. C., Dermen, K. H., Kadden, R., Carroll, I. M. and Frone, M. R. (2000) Predicting the therapeutic alliance in alcoholism $\cdot$ reatment. Journal of Studies on Alcohol, 61: 139-149.

De Jong, P. and Berg, I. K. (2001) Co-constructing cooperation with mandated clients. Social Work, 46: 361-374.

Duncan, B. L. and Miller, S. D. (2000) The Heroic Client: Doing Client Directed, Outcome-Informed Therapy. San Francisco: Jossey-Bass.

Escudero, V., Frielander, M. L., Varela, N. and Abascal, A. (2008) Observing the therapeutic alliance in family therapy: associations with participants' perceptions and therapeutic outcomes. Journal of Family Therapy, 30: 194214. 
Escudero, V., Heatherington, L. and Friedlander, M. L. (2010) Therapeutic alliances and alliance building in family therapy. In J. C. Muran and J. P. Barner (eds) The Therapeutic Alliance. an Evidence-Based Guide to Practice, pp. 240-262. New York: Guilford Press.

Friedlander, M. L., Escudero, V. and Heatherington, L. (2006) Therapeutic Alliances in Couple and Family: an Empirically Informed Guide to Practice. Washington, DC: American Psychological Association.

Friedlander, M. L., Escudero, V., Heatherington, L., Deihl, L., Field, N., Lehman, P. et al. (2005) System for Observing Family Therapy Alliances (SOFTA-o) training manual-revised, retrieved 18 December 2008 from http://www.softasoatif.com/docusofta/softa\%20instruments/manuales/

Softa_CodingManual.pdf.

Friedlander, M. L., Escudero, V., Heatherington, L. and Diamond, G. M. (2011) Alliance in couple and family therapy. Psychotherapy, 48: 25-33.

Higham, J. E., Friedlander, M. L., Escudero, V. and Diamond, G. (2012) Engaging reluctant adolescents in family therapy: an exploratory study of in-session processes of change. Journal of Family Therapy, 34: 24-52.

Honea-Boles, P. and Griffin, J. E. (2001) The court-mandated client: does limiting confidentiality preclude a therapeutic encounter? TCA Journal, 2: 149-160.

Horvath, A. O., Del Re, A. C., Flückiger, C. and Symonds, D. (2011) Alliance in individual psychotherapy.

Imber-Black, E. (1988) Families and Larger Systems: A family therapist's guide through the labyrinth. New York: Guilford.

Lambert, M. J. and Ogles, B. M. (2004) The efficacy and effectiveness of psychotherapy. In M. J. Lambert (ed.) Bergin and Garfield's Handbook of Psychotherapy and Behaviour Change ( $5^{\text {th }}$ edn), pp. 139-193. New York: Wiley.

Madsen, W. C. (2007) Collaborative Therapy with Multi-stressed Families. New York: Guilford Press.

Martin, D. J., Garske, J. P. and Davis, M. K. (2000) Relation of the therapeutic alliance with outcome and other variables: a meta-analytic review. Journal of Consulting and Clinical Psychology, 68: 438-450.

Miller, W. R. and Rollnick, S. (2002) Motivational Interviewing: Preparing People for Change. New York: Guilford.

Nichols, M. P. and Schwartz, R. C. (2006) Family Therapy: Concepts and Methods (7hㅡ edn). New York: Gardner.

Moore, L. E., Tambling, R. B. and Anderson, S. R. (2013) The intersection of therapy constructs: the relationship between motivation to change, distress, referral source, and pressure to attend. American Journal of Family Therapy, 41: $245-258$.

Morris, S. B. and DeShon, R. P. (2002) Combining effect size estimates in metaanalysis with repeated measures and independent-groups designs. Psychological Methods, 7: 105-125.

Pinsof, W. B. (1994) An integrative systems perspective on the therapeutic alliance: theoretical, clinical, and research implications. In A. O. Horvath and L. S. Greenberg (eds) The Working Alliance: Theory, Research, and Practice, pp. 173-195. New York: Wiley.

Prochaska, J. O. and DiClemente, C. C. (1984) The Transtheoretical Approach: Crossing Traditional Boundaries of Therapy. Homewood, IL: Down Jones Irwin. 
Rempel, M. and Destefano, C. D. (2002) Predictors of engagement in courtmandated treatment: findings at the Brooklyn Treatment Court, 1996-2000. Journal of Offender Rehabilitation, 33: 87-124.

Relvas, A. P. (1996) O ciclo vital da família, perspectiva sistémica. Porto: Afrontamento.

Relvas, A. P. (2003) Por detrás do espelho. Da teoria à terapia com a família. Coimbra: Quarteto.

Rooney, R. H. (1992) Strategies for Work with Involuntary Clients. New York: Columbia University.

Snyder, C. and Anderson, S. (2009) An examination of mandated versus voluntary referral as a determinant of clinical outcome. Journal of Marital and Family Therapy, 3: 278-292.

Sprenkle, D. H. and Blow, A. J. (2004) Common factors and our sacred models. Journal of Marital and Family Therapy, 30: 113-129.

Sprenkle, D. H., Davis, S. D. and Lebow, J. L. (2009) Common Factors in Couple and Family Therapy. the Overlooked Foundation for Effective Practice. New York: Guilford.

Sotero, L. and Relvas, A. P. (2012) A intervenção com clientes involuntários: Complexidade e dilemas. Psicologia E Sociedade, 24: 187-196.

Sotero, L., Relvas, A. P., Portugal, A., Cunha, D. and Vilaça, M. (2010) Sistema de Observação da Aliança em Terapia Familiar: SOFTA-o. Versão para Clientes. [Portuguese version of the SOFTA-o for Clients]. Retrieved 14 May 2014 from http://www.softa-soatif.com.

Symonds, B. D. and Horvath, A. O. (2004) Optimizing the alliance in couple therapy. Family Process, 43: 443-455.

Tabachnick, B. G. and Fidell, L. S. (2007) Using multivariate statistics (5 ${ }^{\text {th }}$ edn). Boston, MA: Allyn and Bacon.

Tohn, S. L. and Oshlag, J. A. (1996) Solution-focused therapy with mandated clients: cooperating with the uncooperative. In S. D. Miller, M. A. Hubble and B. L. Duncan (eds) Handbook of Solution-Focused Brief Therapy, pp. 152-183. San Francisco: Jossey-Bass.

Trotter, C. (2006) Working with Involuntary Clients: a Guide to Practice. London: Sage.

Weakland, J. H. and Jordan, L. (1992) Working briefly with reluctant clients: child protective services as an example. Journal of Family Therapy, 14: 231-254. 